\title{
Library and Information and Records Management in the Development of Domestic Discipline Differentiation and Integration
}

\author{
Hui Wang \\ University Library, Jilin Agricultural University, 130118 Changchun, PR China \\ E-mail.13104452100@163.com
}

\begin{abstract}
Along with our country has gone to the information era, economic and comprehensive national strength is constantly growing stronger, library and information sciences and records management disciplines are developing. Differentiation and integration have become the ordinary state of the discipline development of library and information sciences and records management, where integration plays a major role. Library and information sciences and records management will continue to self-improve and develop during the course of the differentiation and integration, not only to promote the improvement of branch disciplines, but also to gradually label them with characteristics of the era. Library and information sciences and records management in our country thus can reach a new level.
\end{abstract}

Keywords-academic development pattern; differentiation; integration; library and information sciences and records management

\section{INTRODUCTION}

In the information age, our country society put "enter the information society" as a key development strategy when we just entered 21th century. In addition, our country also issued a series of related strategic arrangements with "lay a very good basis to enter the information society" as an important goal for our country's economic development. When the social form is under impending transition period, library information sciences and records management disciplines are embodied in his own very important role for the social and economic development and self-improvement, where differentiation and integration become an ordinary state of discipline progress and development. Under such a cross-cutting context, the integration will become a major trend in development of the disciplines.

\section{THE DIFFERENTIATION OF LIBRARY AND} INFORMATION SCIENCES AND RECORDS MANAGEMENT IN THE DISCIPLINE DEVELOPMENT

Concerning the so-called disciplinary differentiation, we generally believe that is the outcome of discipline evolution under the influence of various factors and constant self-development and separation from main disciplines. In real life, however, the discipline differentiation is inevitable issue, and will never stop, no matter which type of subjects they are. Nowadays, our country has library and information sciences and archives management as discipline setting, which in fact the outcome of discipline differentiation. Library and information and records management are currently in a special transition period. This type of discipline differentiation has become a very important part of discipline development, which changes the basic composition and developmental form of the disciplines.

\section{A. The historical process of discipline differentiation concerning library and information sciences and records management}

Currently we have entered a period of rapid development, when literature documenting and recording is more and more. People are using more and more literatures, which makes the use ratio of literatures greatly improved, consequently the custody and preservation of the literatures are becoming difficult and complicated. Literature usage related issues gradually separated from the literature writing and compiling, forming a special working station. Because of the literature usage is increasing, the document management system, standard for rational applications and archiving requirement have increasingly high requirements, which bring about the new disciplines researching literature utilization and knowledge management and protection. In fact, no matter in China or other countries, in contemporary age or ancient times, there is no big difference in books, information materials, and archives; no clear regulation is responsible for their management. Correspondingly, by setting document usage and data storage as a single and combined direction, we can neither distinguish the proper use of literature knowledge from literature maintaining nor have books, materials, archives as corresponding branch disciplines. This can be exemplified by some ancient great masters who can not only use literature to explore a variety of knowledge, but also proficient in manage the documents. There are so many these examples, and I believe everybody can easily pick them up. Along the historical development, people entered industrial society. The specialized scientific division greatly promotes the continuous upgrading of production, while the economical level of society progresses with an unprecedented and steady pace. The number of literatures is exponentially growing, while demand for the use of literature information is constantly increased. Thus, in the field of literature management, a new specific classification also appeared to service others in literature management. This new work career emerged, 
accompanying by the formation of substantial amount of libraries, archives with a modern socialized feature "Literature science" appeared and developed into a sort of discipline, which deals the proper use and storage of information for literature study. Looking over the whole world, library science was initially appeared in the early 19th century, while archives began to rise after less than a hundred years.

Influenced by our own country and outside, especially the arrival of the Opium War descend our country to a semi-colonial and semi-feudal society, where the process of industrialization had been ongoing in a very slow pace, until the establishment of new China in 1949. Until now we has still not stepped into the industrial society. Under such a context, the differentiated development of "scientific literature" is far behind the developed countries. Until the early 20th century, library science began to be separated from "literature science", along with the development of modern "library" with socialization features. At this point library science with a modern sense walked onto the stage in China. In 1930s, as a branch of traditional " literature science" in historical literature research framework, specialized "archives" began to differentiate into a new subject, with the obvious sign of dozens of books regarding archive studies came out in this period.

After the Second World War, science and technology stepped into the peak period of rapid development. During this period, the information continues to grow in an explosive rate. Information is evolved into a very important resource by changing people's uncertainty in recognition. How to preserve information became a social issue for worthwhile discussion. Under such environment, a new discipline information science was formed via a variety of theoretical tool support by fusing the modern computer technology and communication technology, which was differentiated from "literature disciplines". However, in China, "information sciences" was originally used in the scientific and technological innovation, meanwhile this new subject entered the developmental stage.

Through study the developmental process of library and information sciences and records management, it is not difficult to reach a conclusion: library, information and archive sciences are differentiated from the original discipline "literature science" step by step. This differentiation and development undoubtedly has positive significance. In the current information society, these three disciplines have the same characteristics: First, they all rely on the information carrier for recording, meaning that they choose document saving as an object of management. Second, their purpose is the same, to make literature in order and easy to be picked up. Third, the management activities are about the same. They all deal with data collecting, gathering, integrating, storing, and retrieving and how to use.

\section{B. The differentiation characteristics of library and information sciences and archival management}

From the late 1950s to the present era, during the development process library and information sciences and records management were gradually quitted from the mainstream position although never stopping their walking pace, which is the normal outcome following the continuous development and differentiation. The discipline differentiation was focused primarily on continuously forming new disciplines within grade-2 disciplines.

1) The differentiation focuses on not only internal grade-2 disciplines but also new subject branches thrived from grade-2 disciplines

The new disciplines coming out from library and information sciences and records management are from internal grade- 2 instead of grade- 1 disciplines. Two main reasons account for this phenomenon. First, the grade-2 disciplines regarding library and information sciences and records management rely on the law of development of library, information, archival works as a direction, where literature preservation and management are the main content. Although the diversification trend of the literature and documents never stopped, the content and form of which is still based on the three issues mentioned above worldwide. Thus, the library and information sciences and records management did not continue to divide within the grade- 2 disciplines. Second, world is now in an information society. Consequently the development of library and information sciences and records management is no longer focusing on putting various documents in order to facilitate literature searching, but rather devoting themselves to recycle the information resources and effective utilization to a maximum. Therefore, there is no need to have a new grade- 2 discipline even if the document management related business will cover new content besides three issues mentioned above.

\section{THE INTEGRATION OF LIBRARY AND INFORMATION SCIENCES AND DOCUMENTS MANAGEMENT}

Compare to differentiation, differentiation on the basis that it is a higher level of form, generally refers to the interdisciplinary classification on the level of other inquiry and differentiation, integration and mutual integration, the specific performance discipline integration and overall progress. Five years from the beginning of the last century, library information and records management entered a new stage of mainstream forms.

\section{A. The historical development of discipline integration regarding library and information sciences and records management}

In late last century, the value of information resources continue to increase, and information resources in the literature materials become the common concerns of library, information, and archive works, which led to the emergence of "integrated information management". These three disciplines thus formed a new group of subjects. Because of this, in the late 1990s colleges and universities in our country regard this discipline group as a grade-1 discipline under the category of management disciplines.

Looking back the historical development process of library and information sciences and records management, the holding power of integration is derived from the continuous economic development and 
progress. The basic requirement to give the integration is the differentiation of disciplines, which is obtained from knowledge crossing. The improvement and upgrading of library and information sciences and records management is acquired from the constant differentiation and integration.

\section{B. The general way for discipline integration of library and information sciences and records management}

Generally library and information sciences and records management are integrated by means of fusion of the three grade- 2 disciplines within the grade- 1 discipline, albeit also partially rely on external disciplinary crossing.

\section{1) Mutual fusion within grade-1 discipline}

Integration of library and information sciences and records management is dependent on the fusing and crossing of these subjects. Discipline integration means a process of fusing several disciplines together, developing discipline relationship, and formatting a new discipline. Discipline fusion means a process of mutual fusing different disciplines and formatting a new and more powerful discipline. Library and information sciences and records management are the outcome of mutual integration of three disciplines, which not only restores their own characteristics of each discipline, but also improves the basic ability of the discipline. It is a process that follows the law of scientific development and form new things that do not exist in three disciplines. In early 21st century, we walked further into the information age, with information resources expanding continually. At this point, library and information sciences and records management further fuse with each other and also with other disciplines to form a discipline groups such as "information resources management ".

The three splitting disciplines including library and information sciences and records management from gradually formed an independent discipline from "literature science". These separated disciplines have the same characteristics, however this far they have not yet formed an integrated entirety with combined effect. Until 1997, for the first time these three disciplines combined to form an organic whole. From then on our library and information sciences and records management disciplines constantly grew and improved, with disciplinary status sequentially increased. Discipline development also has a very important impact on economic development, which can be verified by a number of issues.

\section{2) Comprehensive crossing of subjects outside of grade-1 disciplines}

The so-called crossing and comprehensive refer to a relative basic way of the external interdisciplinary development of library and information sciences and records. The so-called interdisciplinary crossing refers to the cooperation between two or more disciplines under the same goal and with distinct perspectives for academic exchanges, to solve certain difficult problems and to form a new discipline. The so-called interdisciplinary comprehensive is to combine the exploration methods and to absorb nutrients from multiple disciplines, and to break the boundaries of the original subjects. Following a brand new direction and conducting research across academic disciplines, we are then able to solve certain complex issues, to promote the discipline development and to generate of a brand new discipline. The development of library and information sciences and records management is the outcome of ongoing discipline crossing and integration.

Up to now, most of research on library and information sciences and records management are interdisciplinary projects, which integrate and combine respective advantages with a variety of subjects including mathematics, computer science, telecommunications engineering, business administration, traffic information science, physics, economics, law, journalism, culture, education, sociology, philosophy, history, and philology. There are a lot of problems in process of scientific research on this discipline, which are not problems existed in this subject but belong to part of "social problems". They are gradually formed and associated with society development, which can be also either related to other aspects in life or has a relatively wide and deep impact on other related subjects. Because of this, library and information sciences and records management have to integrate with other disciplines to achieve and improve their enormous capacity. This type of interdisciplinary event is also able to demonstrate the cross and integration of management and science, management and technology, and management and culture.

\section{CONCLUSIONS}

Along with the continuous progress and development of society, we have learned to know the historical developmental process of library and information sciences and records management. Library and information sciences and records management have been shifting their focuses with a clear tendency of approaching economic development, making them "down to earth". The actual social impact of disciplines is now growing, which promotes the development of overall level of whole discipline group of library and information sciences and records management. Some pre-existing prejudices have disappeared, replaced by the understanding and recognition at the bottom of people's heart toward library and information sciences and records management. All of these issues mentioned above constantly promote the vigorous development of different disciplines.

\section{REFERENCES}

[1] Guoqing Huo. Review on domestic information resource management theory. Information Studies: Theory \& Application, 1997 (2): 57-60.

[2] Qiang Bi, Da Yang, Hongmei Huo. Major advances and hot topics in the information resource management in foreign countries. The Journal of the Library Science in China, 2004 (1): 81-84.

[3] Yun Ling, Fan Gao. Advances in the information resource management research abroad from 1995 to 2005. Library Tribune, 2007 (5): 8-12.

[4] Yajun Wang. Theoretical research status and development tendency of national information resource management. Library and Information Service, 2009 (15): 133-137. 
[5] Jiandong Wang. An analysis of domestic IRM research domain basedon bibliographical metrology. Journal of Academic Libraries, 2010 (2):97-104
[6] Jiyuan Ye. An outline of major fields and key research topics of library, information and archives science in the future five years. The Journal of the Library Science in China, 2012 (1): 105-112. 